\title{
En la frontera entre la lingüística y la traductología. Una mirada lingüística
}

\author{
Francisco GARCÍA MARCOS
}

fmarcos@ual.es

Universidad de Almeria (Spain)

Resumen: El artículo examina los puntos de connexion entre la lingüística y la traducción. Para empezar, ese diálogo entre disciplinas científicas debe discriminar dos campos: el de la praxis traductora, de un lado, y el de la traductología, de otro. El primero mantiene claros vínculos con la lingüística descriptive y con la lingüística aplicada. El segundo parece más amplio y está en condiciones de incorporar planteamientos procedentes de la lingüística teórica. El objetivo del artículo consiste en sopesar esas posibilidades y, en la medida de lo posible, trazar las líneas maestras de posibles invetigaciones en esa dirección.

Palabras clave: Lingüística, lingüística aplicada, traducción, traductología

\begin{abstract}
The article examines the connection points between linguistics and translation. To begin with, this dialogue between scientific disciplines must discriminate between two fields: that of translation praxis on the one hand, and that of translatology on the other. The first maintains clear links with descriptive
\end{abstract}


linguistics and applied linguistics. The second seems broader and is in a position to incorporate approaches from theoretical linguistics. The aim of the article is to weigh up these possibilities and, as far as possible, to draw the main lines of possible research in this direction.

Keywords: Linguistics, applied linguistics, translation, translatology

\section{Introducción}

Lo he recordado quizás demasiadas veces, aunque lógicamente he insistido en ello desde las páginas de una revisión cronológica de la lingüística (García Marcos, 2008). La historia humana comienza en Sumer, realmente, como Samuel Noah Kramer había indicado. No nace entonces como un acontecimiento, como actividad humana susceptible de ser rastreada a través de la arqueología. Pero sí que se desarrolla la pericia capaz de dejar constancia del acontecer humano de manera documental. Solo desde hace unos 5000 años se dispone de fuentes escritas, gracias al desarrollo Mesopotamia de esa destreza, de la capacidad para plasmar gráficamente las lenguas.

Esa habilidad social, en cualquier caso, trajo aparejadas más cosas. La escritura nació rodeada de vecindades directamente relacionadas con ella. En ese sentido, permitió establecer leyes, crear mitos colectivos, afirmar la identidad local y, entre otras cosas, preservar las verdades fundamentales de la fe religiosa. Inmediatamente, desarrolló también la correspondiente hermenéutica para la correcta interpretación canónica de los textos producidos, en lo que constituía un ejercicio de poder social inédito hasta ese momento. La ley escrita, por mencionar un caso prototípico, estaba dotada de mayor fuerza social que la oral. 
Desde el principio, las destrezas de la escritura compartieron su camino y buena parte de su suerte social— con la traducción y la interpretación. Solo que en esta ocasión, más que de una relación de vecindad, más bien se coexistía dentro de una hábitats contiguos, sino compartidos. Escritura y traducción (o interpretación) se desenvolvían dentro de una misma sustancia, el lenguaje humano. Además, para el desarrollo efectivo de todas esas destrezas era necesario el mismo requisito: un conocimiento implícito de qué son las lenguas y cómo funcionan.

A veces la historiografía lingüística se ha desenvuelto entre excesiva meticulosidad. En ocasiones incluso ha operado desde parámetros tan restrictivos que la han ceñido a la aparición de una formulación explícita de la lingüística como disciplina autónoma. Una delimitación tan rigurosa equivale a trabajar solo a partir de F. De Saussure. Pero, más allá del celo de algunos historiadores disciplinares, lo cierto es que hubo pasado antes de De Saussure, Whitney, Fortunatov o Bloomfield, naturalmente. Durante siglos, la filología recurrió al conocimiento lingüístico y lo empleó para resolver sus pesquisas históricas o literarias. Por supuesto, ese uso auxiliar del saber lingüístico no equivalía a dotarlo de un estatus propio como forma independiente de conocimiento. Ese logro, indiscutibilísimo, solo cabe atribuírselo a los autores mencionado. Pero, en todo caso, antes había algo más que un vacío disciplinar. Lo cierto es que, aunque de forma subordinada a la filología, se habían estudiado las lenguas, incluso se las había comparado tratando de encontrar reglas evolutivas. Del mismo modo, de una u otra manera, las sociedades se han preocupado por regular el uso formal de sus lenguas, estableciendo sus correspondientes parámetros normativos. Esa línea, la de la lingüística preceptiva que arranca en la Grecia Clásica, ha solido ser uno de los referentes ineludibles para la historiografía lingüística, a poco que se ha mostrado mínimamente flexible. 
En cualquier caso, todavía quedaba más historia científica relacionada con el lenguaje y las lenguas, sobre todo si se mantenían los criterios amplios desde la que acometerla. Para empezar, hubo otras tradiciones tendencialmente preceptivas fuera de la Grecia Clásica, con Panini a la cabeza de los gramáticos orientales. Y para continuar debieron existir otros conocimientos lingüísticos, aunque fuera implícitos, responsables del desarrollo de destrezas como el desarrollo de lenguas artificiales, la elaboración de tablas lógicas de base lingüística o, también, la escritura, la traducción o la interpretación. Estas tres últimas, por lo demás, cumplen sobradamente con la máxima de Kramer. Comenzaron igualmente en Sumer, no solo como una actividad humana, sino como un hecho cultural, además, vinculadas entre sí1.

Desde esos mismos orígenes se ponen de manifiesto algunas de las constantes básicas que regulan las relaciones entre la lingüística y la traductología, un vínculo que no es circunstancial, que no es consecuencia de coordenadas históricas específicas, sino que por el contrario aparece como un nexo tan intrínseco y antiguo como la propia historia humana. Los idiomas siempre se han traducido, o interpretado, simplemente porque esa posibilidad está dentro de las capacidades que admite su propia idiosincrasia, el funcionamiento y la razón de ser de las lenguas. Eso no implica incluirlos sin más dentro la misma disciplina en términos modernos. La traducción y la lingüística se basan en sólidos fundamentos epistemológicos. Pero es cierto que la interdisciplinariedad que se puede desarrollar entre ellos es singular, precisamente por ese punto de encuentro epistemológico, por el examen de la facultad humana para transferir contenidos de una lengua a otra.

\footnotetext{
${ }^{1}$ Sobre mi perspectiva en relación a la historia de la lingüística y sus orígenes, cfr. García Marcos (2008).
} 


\section{La direccionalidad epistemológica de la lingüística y la traductología}

A pesar de ello, los vínculos modernos entre la lingüística y el mundo de la traducción tardaron en desarrollarse de manera explícita y sistemática. Hurtado Albir (1996: 155) sitúa su arranque entre los años cincuenta y sesenta, fecha en la que se produciría la integración de la traducción dentro de la lingüística aplicada. No deja de ser un planteamiento solvente y contrastable, en el que por lo demás coincidía con lo apuntado en su día por autores como Fedorov (1953), Vinay y Dalbernet (1958), Mounin (1963) o Catford (1965).

Sin embargo, tenía también sus inconvenientes. En sentido estricto, la lingüística aplicada no comenzó a definirse hasta principios de la década de 1960. Inicialmente, estuvo vinculada a la enseñanza de lenguas extranjeras, casi monográficamente (Calvo, 1996). Solo a finales de ese período, se empezaron a incorporar nuevas aplicaciones, por lo demás sin conciencia explícita de adscribirse a una rama, la aplicada, que en aquellos momentos no figuraba $-\mathrm{y}$ casi ni se presagiaba - en la topología disciplinar. En primer lugar, lo hicieron la planificación lingüística (procedente de la sociología del lenguaje) y la lingüística computacional, ambas en estado ciertamente embrionario por aquellas fechas. La sociolingüística estaba terminando de perfilar una profunda actualización de su modelo, evolucionando desde la dialectología social en EE. UU., ampliando la tradición que había inaugurado Meillet en Europa, prácticamente desde la primera década del siglo XX (García Marcos, 1999). La informática, que justo en esas fechas trataba de confirmarse como ciencia y como técnica, estaba lejos de lo que ha sido su espectacular desarrollo posterior. Pero había sido capaz de presentar desarrollos lingüísticos desde el principio del desarrollo de sus sistemas expertos (García Marcos y Mateo, 2019). A continuación, se incorporó la 
enseñanza de la lengua materna, no tanto como el desarrollo de un nuevo campo de aplicaciones, sino como una reorientación científica de viejas preocupaciones. En rigor, la mayoría de las sociedades se han ocupado de la transmisión de su propia lengua, de una u otra forma. La tradición preceptiva a la que me he referido hace un instante no dejaba de comportar inquietudes de ese tipo. Trasladarlas a los dominios de la aplicación, en todo caso, implicaba un cambio sustancial en su orientación, tanto como abandonar el antiguo enfoque preceptivo por otro más acorde con los procesos psicológicos y sociales que rigen el desarrollo del lenguaje humano.

Habrán de pasar casi dos décadas más para que la lingüística jurídica y la lingüística clínica se asienten por completo. Solo entonces, a mediados de la década de los 90 , se dispone de una lista relativamente estable de aplicaciones lingüísticas, en la que -ya sí- por supuesto que se incluyen vínculos interdisciplinares con la traducción. Pero ese panorama lo suficientemente nítido por ambas partes - por la lingüística aplicada que tuvo que delimitarse y por sus nexos con la traductología - solo se delinea cuatro décadas más tarde de lo previsto por la bibliografía.

Con todo, el desajuste cronológico que acaba de comentarse es verdaderamente relevante de la clase de relación interdisciplinar que se ha ido consolidando con los años. En sentido estricto, la traducción no aparece en la genealogía histórica de la lingüística aplicada que han propuesto los propios lingüistas. Sin embargo, en la percepción de los traductores parece ser un hecho contrastado. De manera que el comienzo de esa vinculación interdisciplinar fue en apariencia complicado y, por descontado, resultó extraordinariamente paradójico.

Hoy el panorama se antoja notablemente más aclarado, sobre todo porque todos los agentes científicos implicados han alcanzado un mayor punto de 
consolidación. Lingüística y traducción sigue compartiendo, por supuesto, su tradicional punto de convergencia, el lenguaje y las lenguas., solo que lo abordan desde perspectivas científicas y necesidades sociales suficiente y claramente diferenciadas. Desde esa consolidación epistemológica a la que acabo de referirme, es más factible proponer una sólida confluencia interdisciplinar. Traducir no consiste en aplicar, sin más, la lingüística. Cosa distinta es que esta, en todos sus niveles, esté en condiciones de contribuir al trabajo de los traductores e intérpretes. De la misma forma, en la dirección inversa, parte de las decisiones que se adopten en la práctica traductora muy probablemente estén en condiciones de aclarar a los lingüistas algunas cuestiones relevantes en relación al funcionamiento de las lenguas.

En la etapa fundacional de la traductología, Holmes (1972) estableció unas coordenadas considerablemente amplias y que siguen ponderadas, en gran medida todavía vigentes en la actualidad. Holmes (1972) abordó la problemática de los modelos y los métodos traductológicos, desde una epistemología disciplinarmente autónoma. Esa configuración de una personalidad científica propia y diferenciada no entraba en contradicción, antes todo lo contrario, con una marcada vocación de diálogo y colaboración con otras disciplinas. En ese sentido, defendió que la traducción amalgamaba un conjunto muy diversificado de elementos: lingüísticos, psicológicos, sociológicos o, entre otros, culturales. Cada uno de ellos abría posibilidades efectivas de trabajo con otras ciencias, sin tener que renunciar a su propia identidad científica.

Ese planteamiento ha gozado de reconocimiento y apreciable consenso, al menos visto desde la distancia de una disciplina contigua como la lingüística. Cuando en 2009 Campos Plaza retoma la discusión sobre la situación de la traducción en su tiempo, sigue una línea no tan lejana a Holmes, desde la que hace acopio de gran rigor y ponderación, renunciando desde el principio a 
planteamientos maximalistas. La juventud de la disciplina y su heterogeneidad interna aconsejan moderación para Campos Plaza (2009: 276-277), sin que ello implique renunciar a subrayar que todo proceso de traducción implica la aproximación de dos sistemas (la fuente y la meta), subespecificados a su vez en varios niveles: lingüístico, cultural, sociológico.... Como quiera que cada uno de estos ejes conlleva la posibilidad de acercarse a otros campos del conocimiento, finalmente concluye su análisis reafirmando una perspectiva interdisciplinaria para la traductología, de acuerdo una vez más con el enfoque de Holmes.

\section{El estatus de la lingüística en la topología interdisciplinaria de la traductología}

Los enfoques de Holmes o Campos Plaza encuentran perfecto acomodo entre las coordenadas de una lingüística actual que, desde los años 60, ha vivido una profunda transformación con un cambio muy sustancial en sus objetivos. A partir de esa década, se ha desarrollado y depurado lo que Pisani (1987) denominó "paradigma dinámico". Entre otras cosas, esa nueva perspectiva desplazó el estudio de las estructuras o los procesos generativos como núcleo exclusivo de los intereses lingüísticos, para enfatizar el análisis del uso lingüístico. Las lenguas ya no se entienden como meros inventarios de formas y estructuras. Tampoco basta con presuponer su hipotética -e indemostrable - trayectoria desde las profundidades de la mente humana. La lingüística con la que termina el siglo XX ha querido saber cómo se utilizan las lenguas en sus contextos concretos de uso. Y al acercarse a esta realidad empírica más amplia, ha tendido inevitablemente a encontrarse con otras disciplinas. El uso lingüístico, por fuerza, había de abrirse a los marcos interdisciplinares entre los que discurre la vida de las lenguas. Tanto es así que una de las grandes referencias de este paradigma 
dinámico, la ciencia del texto de T. Van Dijk, (1978), concluye proponiendo una clara e intensa convergencia entre campos de conocimiento, más que conexos, co-implicados.

Por lo tanto, la opción interdisciplinar no le resulta ajena a la lingüística más moderna, aunque con matices. Para un lingüista la puntualización más significativa probablemente radique en la jerarquía implícita desde la que deban operar las disciplinas implicadas en la propuesta traductológica. Todos esos posibles vínculos señalados hace un instante no parecen ser materia discutible, cuando menos tal y como han sido propuestos. Solo que, al mismo tiempo, se diría que los lingüísticos resultan más intensos que los restantes. Se produce traducción cuando se registra una transferencia de un sistema sociolingüístico a otro. Este es el hecho nuclear a partir del cual se articulan todos los demás. Todo ello, además, concuerda con la ampliación epistemológica que ha introducido el paradigma dinámico en lingüística, gracias a la que son posibles este tipo de formulaciones. La atención al uso precisamente subraya que las lenguas son instituciones sociales (dimensión sociológica), que transportan culturas (dimensión antropológica y cultural) o que activan mecanismos mentales (dimensión psicológica).

Así pues, parece conveniente insistir en los nuevos presupuestos teóricos entre los que la lingüística ha estado discurriendo a partir de los años sesenta. Tal vez la imagen social de la lingüística no se corresponda con su evolución disciplinar, y persista el tópico de que los lingüistas continúan elaborando grandes inventarios de formas, o buscando estructuras profundas, o incluso estableciendo modelos normativos. En el pasado, por supuesto, que fue así, y tampoco es cuestión de abjurar de una tradición disciplinar que, con sus limitaciones y sus logros, consiguió asentar y solidificar la disciplina. El antiguo paradigma lingüístico comportaba sus limitaciones de cierta envergadura para su 
posible colaboración con la traducción, toda vez que se ceñía a comprobar cómo se transferían las estructuras de un idioma a otro. La lingüística de contrastes era una herramienta comúnmente utilizada para esos cometidos y ofrecía resultados sin duda interesantes. Pero la propia lingüística ha reclamado más información, sobre todo de cara a incluir los factores sociolingüísticos, pragmáticos o textuales, imprescindibles para explicar cómo se articula y funciona la realidad cotidiana de las lenguas. Y justo esta última perspectiva es la que interesa a una traductología que aspire a tener una mirada más amplia, también más fundamentada en la realidad empírica.

Hay que reconocer que la traductología ha estado muy atenta a esta evolución interna de la lingüística. En 2016 Ortega y Caprara exploraron con éxito la incorporación de la sociolingüística al campo de la traducción. Para ello, colaboraron con J. A. Villena, experto en variacionismo, que no parece la versión sociolingüística de más fácil e inmediata vinculación a la traducción. El variacionismo examina la estratificación social de las lenguas utilizando procedimientos estadísticos relativamente específicos. Gracias a ellos, se accede a una parte de la vastísima interrelación que mantienen las lenguas y las sociedades. Se sabe cómo se distribuyen socialmente las variantes de uso de las lenguas en sus comunidades de habla, aunque queda, ni más ni menos, que todo lo demás: el valor simbólico de los hechos lingüísticos, los condicionamientos sociológicos que reciben las lenguas, los perfiles ideológicos que denota y que alimentan, su dinamismo en el micronivel, la confluencia con otros lenguajes semióticos, un larguísimo y prolijo etcétera. Pero incluso en este supuesto extremo, Caprara y Ortega demostraron que se obtenían resultados positivos para el traductor. Una mayor penetración en los entresijos de la variación sociolingüística permitió acceder a una comprensión más profunda de la dimensión de uso del lenguaje, de lo que se derivaba un traducción más sólida y fundada. 
Si el resultado ha sido tan exitoso en el supuesto variacionista, cabe suponer que otros modelos sociolingüísticos permitirán resultados aún mejores. La etnografía del habla, la sociología de la lengua, la escuela italiana o sociolingüística integral parten de posiciones más cercanas a las colaboraciones interdisciplinarias que, de hecho, cuentan con una tradición exitosa y asentada². Por lo tanto, la contribución de Caprara y Ortega abría posibilidades más que atractivas para el futuro.

Es cierto que esta atención a la lingüística más reciente ha conllevado ciertos riesgos. Sánchez (2005) propuso abordar la traducción como un caso de lenguas en contacto. En términos sociolingüísticos, el contacto entre lenguas presupone socialización y a menudo implica diglosia (García Marcos, 2015). Básicamente se registra cuando coexisten diversos grupos sociales con diferentes idiomas dentro del mismo espacio social que comparten. La traducción y la interpretación no presuponen necesariamente una situación de esas características. Los textos del Dalai Lama han sido traducidos al español, aunque nunca ha habido una coexistencia idiomática entre España y el Tíbet. También puede darse el supuesto contrario: el contacto entre lenguas no conduce necesariamente a la actividad traductora. A pesar del contacto secular entre aranés y español, nadie ha traducido al español los poemas de Mosén Condó Sambeat, el fundador de la literatura aranesa moderna a finales del siglo XIX. Tampoco tengo conocimiento de la existencia de una traducción de César Vallejo al aranés.

Por lo tanto, sería preferible hacer acopio de prudencia y permanecer en los dominios sociolingüísticos del bilingüismo, una de las posibles consecuencias

\footnotetext{
${ }^{2}$ La sociolingüística es fundamental para el desarrollo de la semiótica italiana a principios de los 60, y viceversa. Del mismo modo, Hymes y Gumperz acuden a herramientas etnográficas que adaptan al supuesto de la interacción verbal, también al final de esa década y principios de la siguiente. Cfr. García Marcos (1999).
} 
del contacto entre lenguas (no todo su abanico de resultantes), y hacerlo no sin precauciones. Tampoco está claro que el bilingüismo genere de manera sistemática procesos de traducción en sus interacciones más habituales. Ha habido mucha discusión sobre la estructuración y el funcionamiento de la mente bilingüe, sobre sus mecanismos cognitivos, su desarrollo evolutivo, su influencia en los procesos educativos o el tipo de almacenamiento de información que tienen estos hablantes. Para esta última cuestión se han propuesto dos modelos básicos. Por un lado, se ha postulado la existencia de un concepto único, que se asigna a dos etiquetas (un significante en cada idioma). Así, un bilingüe catalán/castellano tendría

-Un concepto: "Mamífero solípedo del orden de los perisodáctilos, de tamaño grande y extremidades largas, cuello y cola poblados de cerdas largas y abundantes, que se domestica fácilmente y suele utilizarse como montura o animal de tiro". (DRAE)

- Dos significados, "caballo" (castellano) y "cavall" (catalán).

La otra posibilidad consiste en duplicar el concepto y la asignación de etiquetas. En este caso se admite que cada lengua desarrolla su propia cosmovisión, por lo que el concepto de "caballo" no es exactamente equivalente en castellano y catalán (o en cualquier otra lengua).

De todas formas, en ambas posibilidades parece claro que el bilingüe no traduce exactamente, sino que reelabora sus mensajes. Analizando la estructura psicológica del bilingüismo, M. Siguán (1976) señaló que este transita de una lengua a otra, no que un contenido lo vierte a otra. El matiz es muy importante en esta ocasión. Para Siguán, un idioma no se transforma en otro, sino que es el 
hablante quien se traslada de un idioma a otro. De manera que cada lengua viene a ser una especie de ubicación psicológica, con sus correspondientes reglas, que no son exactamente equivalentes entre sí. Para ilustrar su planteamiento Siguán (1976: 18) acude a una anécdota protagonizada por Julien Green ${ }^{3}$. Bilingüe francés/inglés, se le pidió que tradujera una de sus novelas, escrita originalmente en francés. Se negó rotundamente, argumentando que esto le obligaría a volver a escribirla.

Este parece un marco más acorde con los cometidos de la traducción y la interpretación, siempre desde un alto grado de singularidad. Un hablante bilingüe interactúa en situaciones ordinarias, que tienen un grado de formalidad variable. El traductor, o el intérprete, transfiere interacciones lingüísticas a otros hablantes, lo que incluye la contextualización entre las que se han desenvuelto. Precisamente los destinatarios de sus mensajes se caracterizan por no ser bilingües en uno de los dos idiomas involucrados. Si lo fueran, no necesitarían su intervención.

\section{La heterogeneidad de la traductología}

Al colaborar con traductores e intérpretes, los lingüistas deben ser conscientes de que van a penetrar en un ámbito extraordinariamente heterogéneo. Entre los especialistas (Hurtado Albir, 1996) existe una clara frontera que separa un "saber hacer" (traducción) de un "conocimiento científico" sobre lo anterior (traductología). La lingüística tiene poco que decir al respecto. Para empezar, es un asunto interno que solo puede observarse a distancia. Y para

\footnotetext{
${ }^{3}$ De familia estadounidense, nació, creció y vivió en Francia. Autor prolífico, Green (19001998) publicó en francés e inglés, además de ejercer como traductor e intérprete de ambas lenguas.
} 
continuar, en todo caso, se antoja una distinción bastante razonable. En ambos casos, además, existen posibilidades inmediatas de colaboración sin demasiados problemas, tanto con traductores como con traductólogos.

\section{Traducción y lingüística}

Empezando a concretar esas posibles vías de colaboración, habrá que reconocer que la lingüística ha mantenido vínculos milenarios con la traducción. Volviendo a Mesopotamia, existen diccionarios sumerios/acadios documentados en escritura cuneiforme. Respondieron a una necesidad inmediata en esa sociedad. Durante la hegemonía sumeria se habían producido textos fundacionales, especialmente en derecho, literatura épica y religión. El cambio de hegemonía política a otra ciudad, Akkad, no eliminó estas referencias culturales y administrativas. Por lo tanto, se planteó la necesidad de constituir una casta de especialistas capaces de pasar de una lengua a otra. Asimismo, la diplomacia y las relaciones con otras ciudades requirieron de expertos capaces de conocer a fondo otras lenguas extranjeras, los intérpretes, que también aparecen en los textos mesopotámicos.

A partir de ese momento, desde el principio de la historia documentada, los diccionarios han sido compañeros habituales de los traductores. A veces incluso se podría decir que fueron sus clientes más destacados. Desde el Renacimiento, proliferaron los diccionarios multilingües, consecuencia inmediata de las grandes transformaciones sociolingüísticas experimentadas en Europa. Hasta entonces, los idiomas locales se consideraban lenguas vulgares. Los registros elevados habían quedado exclusivamente para el latín durante toda la Edad Media. Pero a partir del siglo XVI, el desarrollo de los estados nacionales 
condujo al auge sociolingüístico de sus lenguas., que dejaron de estar ubicadas en los más modestos rincones de los repertorios funcionales de sus respectivas comunidades para convertirse en instrumentos formales de comunicación. Sucedió incluso en la ciencia. Descartes recomendó escribir en la lengua materna porque la consideraba más cercana al pensamiento puro (García Marcos, 2003), lo que implicaba que esos académicos modernos, alejados del latín como lingua franca del conocimiento, habían de manejar otros idiomas extranjeros y/o que disponer de las pertinentes traducciones especializadas. Otro tanto ocurrió en la diplomacia o en las transacciones comerciales. Un mundo abierto a la pluralidad lingüística requería necesariamente de traductores e intérpretes. Los diccionarios políglotas, pues, encarnan esa nueva realidad, a la vez que ofrecen valiosas herramientas para el inmediato contraste entre lenguas.

Por supuesto, las utilidades relacionadas con el léxico han ido evolucionando al mismo tiempo que su desarrollo dentro de la lingüística. En los últimos años, se ha destacado el papel de la terminología en la traducción especializada (Cabré, 2000). Las unidades terminológicas son núcleos de conocimiento lexicalizado (Sager, 1992), por lo que localizan y ordenan el mundo cognitivo del hablante (Meyer, 1996, 1997; Pozzi, 1999) y en consecuencia también del traductor (Faber, 2010). Esta colaboración, ya de por sí muy positiva, marca una de las grandes referencias de la futura lingüística aplicada en el ámbito de la traducción.

Desde la época clásica, la gramática también ha sido el otro destacado instrumento lingüístico empleado dentro de la traducción. En su evolución milenaria, desde Dionisio de Tracia hasta nuestros días, los estudios gramaticales han ofrecido modelos normativos, sistematizaciones estructurales de sus componentes y contrastes entre lenguas. Todos ellos han tenido su parte de utilidad en la traducción a lo largo de la historia, entre otros motivos, porque 
fueron los referentes ejemplares por los que se guiaron las interacciones verbales en los registros más formales de sus respectivas comunidades.

La lingüística dinámica incrementó el número y el tipo de herramientas a disposición de traductores e intérpretes, sobre todo porque los aproximó con mayor precisión a los parámetros de funcionamiento ordinario de las lenguas. Es ahí, en esa lingüística más reciente, de donde pueden extraerse informaciones pragmáticas, sociolingüística, del análisis del discurso, la lingüística cognitiva o la gramática del texto, todas ellas con un extraordinario valor empírico para adentrarse en la urdimbre de las lenguas y el lenguaje, como se ha señalado más arriba. La propuesta de Caprara y Ortega apuntaba, sin duda, en esa dirección que, además, implícitamente conlleva discriminar varios tipos y grados de especialización de la contribución lingüística al campo de la traducción y la interpretación. Es probable que no todos sus ámbitos tengan las mismas necesidades lingüísticas, lo que no significa que cada una de ellas no acabe encontrando elementos de utilidad en ese amplio espectro empírico que aporta la lingüística más reciente. En todo caso, parece evidente que la traducción audiodescrita habrá de recomponer las secuencias pragmáticas con mayor detalle que en otras traducciones. El doblaje, en cambio, es probable que muestre mayor interés por la variación estilística asociada a los niveles fónicos. Al traducir textos religiosos, por su parte, habrá de prestarse singular atención a evitar los tabúes lingüísticos. El subtitulado, en fin, deberá prestar atención a las diferencias entre los sistemas de representación gráfica. La lista quizá no sea ilimitada, aunque sí parece razonablemente extensa. Todos esos En todos estos casos comparte un elemento constante y un elemento común. Los datos lingüísticos son una referencia útil para el "saber hacer". Por eso tienen un marcado carácter instrumental. Luego queda la otra parte, la del "conocimiento científico", para que la interdisciplinariedad con la traducción requiere de la lingüística teórica. 


\section{Una propuesta de hipótesis para el futuro}

Parece evidente que la globalización requiere de procedimientos cada vez más elaborados que sean capaces de gestionar la comunicación de manera eficiente. Por supuesto que, como fenómeno histórico y sociológico, la globalización transciende lo meramente comunicativo, por más que este sea un componente imprescindible para su funcionamiento. Pero el hecho es que ha desarrollado una economía global, ha eliminado numerosas fronteras, ha creado estructuras transnacionales, ha establecido rutas internacionales de circulación y, entre otras cosas, ha homogeneizado la cultura. El funcionamiento de ese haz de circuitos, con sus correspondientes interconexiones, requiere necesariamente de una comunicación cada vez más experta que aplique conocimientos lingüísticos de última frontera. El reto es, sin duda, de envergadura, habida cuenta de que, por primera vez en su historia milenaria, la lingüística ha sido capaz de producir acumulación de capital, probablemente de manera involuntaria y sin ser plenamente consciente de ello. A la vez, el desafío que ello implica no deja de ser menos apasionante.

En todo caso, el papel de la comunicación verbal en la globalización no puede entenderse sin la compañía de traductores e intérpretes. Estas estructuras globales requieren de traducción e interpretación, prácticamente de forma continua. Se produce en esta ocasión otro hecho solo aparentemente paradójico. La traducibilidad resulta imprescindible en ese marco globalizador en un doble sentido: como instrumento que desarrolla y consolida las dinámicas globalizadoras, pero también como garante de la preservación de las identidades minoritarias. Cuantas más traducciones tengan las instrucciones de un electrodoméstico, mayor será la audiencia potencial a la que podrá acceder, por 
acudir a un ejemplo tan evidente como cotidiano. Pero también traducir ese folleto al bretón, al quichua o a cualquier lengua minoritaria no deja de ser una forma de prolongar su supervivencia. De la suma de ambas tendencias surge un hecho contrastable. Nunca ha habido un volumen de traducción e interpretación comparable al registrado hoy en día. Una idea en la que insistió Emilio Ortega Arjonilla, con toda justicia.

En esta dinámica, la discriminación entre herramientas, resultados y fundamentos científicos pierde fuerza en términos absolutos. No es que deje de ser epistemológicamente relevante. Pero sí debilita sus límites, ya que en la práctica estos tres niveles se correlacionan. Para obtener mejores resultados se requiere de herramientas más ajustadas y exactas, que provendrán de teorías más exigentes. Si una empresa de marketing necesita un asesor lingüístico, será aconsejable que cuente con un experto en lingüística pragmática, análisis del discurso o sociolingüística. Las huellas dejadas por el paso de la estructura profunda a la superficial no parecen resolver problemas específicos, excepto los planteados por el propio generativismo. Incluso en lo que parecía ser su gran dominio de aplicación, la inteligencia artificial, los postulados de Chomsky y sus seguidores han mostrado graves deficiencias. El formalismo generativista ha terminado siendo ineficaz, por lo que ha sido necesario recurrir a la lingüística de corpus. Esto significa que han ido al extremo opuesto, al máximo empirismo lingüístico posible, para inferir las reglas estructurales de las lenguas naturales.

Por lo tanto, existen modelos teóricos con mayor potencial de aplicación que otros, de los que se derivan instrumentos más útiles (que otros, igualmente). Al menos así sucede con la mayoría de las aplicaciones en las que está interviniendo la lingüística actual.

Naturalmente, en el caso de la traducción, es el tradcutor/mediador, tal y como lo propone Campos Plaza, quien decide qué usar y qué descartar, si bien 
esta es una cuestión que rebasa con claridad los límites estrictos de la lingüística. Su responsabilidad en relación con la traductología debe concentrarse en el desarrollo de herramientas más precisas y en ofrecer modelos lingüísticos más exhaustivos. Son dos componentes distintos que conviven sin mayores problemas dentro de su topología científica, aunque obviamente correlacionados: el primero es parte de la lingüística aplicada, el segundo está integrado dentro de la lingüística teórica. La propia práctica de traducción selecciona las posibles opciones que la lingüística puede ofrecer a sus profesionales, lo que no excluye que existan modelos lingüísticos que a priori faciliten (o dificulten) esa tarea. El traductor/mediador, en el fondo, viene a actuar como un intermediario entre un texto fuente y uno (o varios) destinatarios. Es una tarea que se acomoda a los presupuestos de la etnografía del habla. En su actividad de mediación, el traductor introduce un evento comunicativo (fuente) para convertirlo en un nuevo evento (meta). No basta con encontrar la palabra o una estructura similares en el inventario de las formas lingüísticas. Se trata de una tarea más compleja, que requiere personas con dos habilidades comunicativas equivalentes, por supuesto, en los idiomas implicados en el ejercicio de traducción.

Probablemente desde el punto de vista del evento comunicativo, una buena parte de las cuestiones que se han planteado en los capítulos anteriores pueden ser resueltas. Seguir perseverando en esa dirección fue la penúltima tarea científica que me encomendó Emilio.

En ello estoy. 


\section{Bibliografía}

Cabré, M. T.

2000. "El traductor y la terminología: necesidad y compromiso" en Panace, 1(2): 2-4.

Campos Plaza, N.

2009. "Los límites de la investigación traductológica" en Revista de Investigación Lingüística, 12: 275-287

Caprara, G.; E. Ortega Arjonilla y J. A. Villena.

2016. Variación lingüística, traducción y cultura: de la conceptualización a la práctica profesional. Frankfurt am Main: Peter Lang.

Catford, J. C.

1965. A linguistic theory of Traslation. Oxford: Oxford University Press.

Cerdá R.

1990. "Si Chomsky hablara kikuyu". Actas del Congreso de la Sociedad Española de Lingüistica:(Tenerife, 2-6 de abril de 1990). Madrid: Gredos, 903-912.

Chuquet, H. y M. Paillard.

1989. Approche linguistique des problèmes de traduction. Paris: Ophris.

Faber, P.

2010. "Terminología, traducción especializada y adquisición de conocimiento." La traducción en contextos especializados. Propuestas didácticas, 87-96. 
García Marcos, F.

1999. Fundamentos críticos de sociolingüística. Almería: Universidad de Almería.

2003. "El lenguaje científico y la política lingüística internacional en tiempos de Descartes" en Lengua, variación y contexto: estudios dedicados a Humberto López Morales. Madrid: Arco Libros., 283-316.

2008. Historia social de la lingüística. Barcelona: Octaedro.

2015. Sociolingüística. Madrid: Síntesis. y M. V. Mateo.

2019. "Los estudios de disponibilidad léxica en la fundamentación de la moderna lingüística aplicada en España" en Ogigia, 25: 31-55.

Guillemin-Flescher, J.

1981. Syntaxe comparée du français et de l'anglais. Problèmes de traduction. Paris: Ophris.

Halliday, M. A. K.

1977. El lenguaje como semiótica social. México: FCE, 1979

Hurtado Albir, A.

1996. "La traduction: clasification et éléments d'analyse" en Meta, 41, 3: 366-377.

Meyer, I. y K. Mackintosh.

1996. "Refining the terminographer's concept-analysis methods: How can phraseology help?" en Terminology, 3(1): 1-26.

Meyer, I.; K. Eck y D. Skuce.

1997. "Systematic concept analysis within a knowledge-based approach to terminology" en Wright, Sue Ellen and Gerhard Budin (eds.): Handbook 
of Terminology Management. Amsterdam/Philadelphia, Amsterdam: John Benjamins, 98-118.

Mounin, G.

1963. Les problèmes téoriques de la traduction. Pari: Gallimard.

Muñoz Martín, R.

2008. "Apuntes para una traductología cognitva. Pegenaute, L.; Decesaris, J.; Tricás, M. y E. Bernal [eds.] Actas del III Congreso Internacional de la Asociación Ibérica de Estudios de Traducción e Interpretación. La traducción del futuro: mediación lingüístca y cultural en el siglo XXI. Barcelona: PPU. Vol. 2: 65-75.

Pisani, A.

1987.La variazione linguistica. Causalismo e probabilismo in sociolinguistica. Torino: Agnelli.

Pozzi, M.

1999. "The concept of 'concept' in Terminology: a need for a new approach". Sandrini, Peter (ed.), TKE'99 Terminology and Knowledge Engineering Proceedings. Vienna: TermNet.

Sager, J. C.

1992. "The translator as terminologist" en Dollerup, C. y A. Loddegaard (eds.) Teaching Translation and Interpreting Training, Talent and Experience. Amsterdam: John Benjamins, 107-122.

Sánchez, I. S.

2005. "La traductología: estudio de lenguas en contacto"en Hermēneus. Revista de Traducción e Interpretación, 7: 1-11. 
2019. "En la frontera entre la lingüística y la traductología. Una mirada lingüística" Sabir. International Bulletin of Applied Linguistics, 1: 87-109

Siguán, M.

1976. "Bilingüismo y personalidad" en Anuario de psicología/The UB Journal of psychology, 15: 15-36.

\section{Van Dijk, T.}

1978. La ciencia del texto. Barcelona: Paidós, 1992.

Vinay, J. P. y J. Darbelnet.

1958. Stylistique comparée. Stilistique comparée du français et de l'anglais. Méthode de traduction. Paris: Ophris. 